ENCYCLOPEDDIE Encyclopédie berbère

BERBERE

3 | 1986

3 | Ahaggar - Alī ben Ghaniya

\title{
Ain Roua
}

\section{G. Camps}

\section{OpenEdition}

Journals

Édition électronique

URL : http://journals.openedition.org/encyclopedieberbere/841

DOI : 10.4000/encyclopedieberbere.841

ISSN : 2262-7197

\section{Éditeur}

Peeters Publishers

\section{Édition imprimée}

Date de publication : 1 juillet 1986

Pagination : 337-338

ISBN : 2-85744-260-2

ISSN : 1015-7344

\section{Référence électronique}

G. Camps, «Ain Roua », Encyclopédie berbère [En ligne], 3 | 1986, document A121, mis en ligne le 01 décembre 2012, consulté le 15 octobre 2020. URL : http://journals.openedition.org/ encyclopedieberbere/841; DOI : https://doi.org/10.4000/encyclopedieberbere.841

Ce document a été généré automatiquement le 15 octobre 2020

(c) Tous droits réservés 


\section{Ain Roua}

\section{G. Camps}

1 Village situé au pied du Djebel el-Anini, dans le Guergour (wilaya de Sétif, Algérie). Cette localité agricole, à proximité de laquelle fut exploité un petit gisement de zinc (calamine du Guergour), a conservé, à peine déformé, le nom d'Horrea que l'Itinéraire d'Antonin donne à une agglomération située entre Thubusuptu (Tiklat, dans la vallée de la Soummam) et Sitifis, éloigné d'Horrea de 18 milles pas, ce qui correspond à la distance de Sétif à Aïn Roua.

2 Il est possible que les greniers qui donnèrent leur nom à la localité romaine étaient ceux de l'Annone*; il existait dans la région un Saltus horreorum dont le chef-lieu (Caput Saltus Horreorum) était à Aïn Zada, à quelque $20 \mathrm{~km}$ au sud d'Aïn Roua. D'autres toponymes tirés d'horrea sont connus en Afrique du Nord: Hergla (Horrea Caelia) au nord de Sousse, en Tunisie, Ouréah, à l'ouest de Mostaganem, en Algérie. La fréquence relative de ce toponyme explique qu'il soit accompagné d'un qualificatif (Horrea Caelia), celui d'Aïn Roua était Aninicensis ; au Concile de Carthage de 411 était présent en effet un Cresconius episcopus ab Horrea Aninicensi. Ce nom est conservé aujourd'hui par le Djebel el-Anini.

3 Les ruines d'Horrea ont disparu lors de la construction du village moderne, elles n'ont malheureusement jamais fait l'objet de fouilles. Aïn Roua a livré plusieurs inscriptions et une curieuse vasque en pierre que l'on suppose avoir été placée à l'entrée d'une basilique pour permettre aux fidèles de faire leurs ablutions. Cette vasque d'un diamètre de $73,5 \mathrm{~cm}$ et d'une hauteur de $21 \mathrm{~cm}$ est manifestement inspirée d'une poterie en terre cuite dont elle reproduit l'anse qui est disproportionnée et inutilisable. 


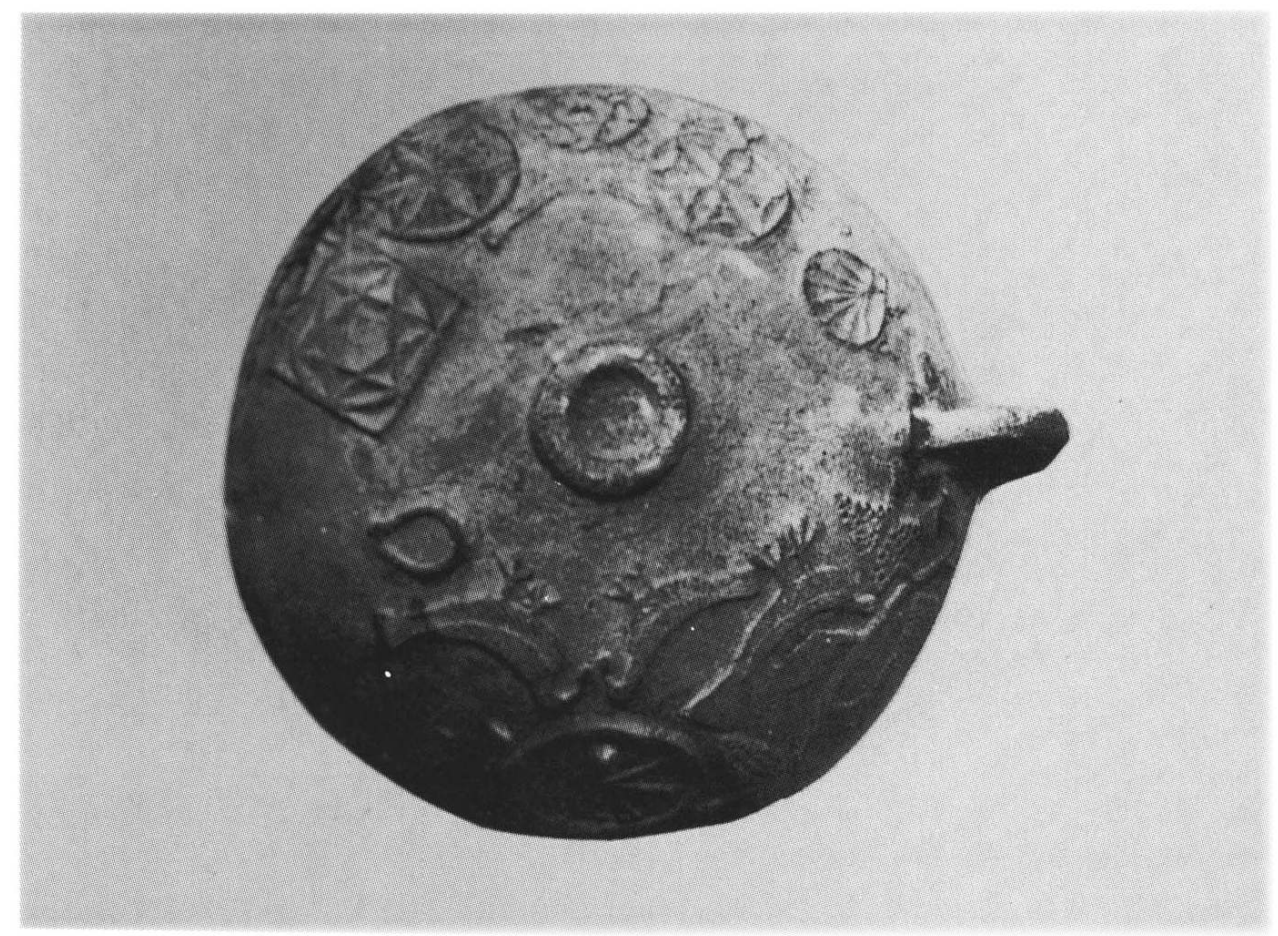

4 Le décor sculpté sur les parois,à l'extérieur, est celui des monuments chrétiens : le chrisme dans un médaillon, des grappes de raisin que picorent des colombes, un gâteau d'offrande, motifs végétaux divers et d'autres géométriques imités du décor en champlevé sur bois ou sur plâtre (rosaces, hexagrammes, sceaux de Salomon) mais ici ces motifs sont en léger relief.

\section{BIBLIOGRAPHIE}

GSELL S. Atlas archéologique de l'Algérie, feuille 16, Sétif, n. ${ }^{\circ} 78$.

PAVIS D'ESCURAC-DOIZY H. Vasque chrétienne d'Ain Roua. Libyca, Archéologie, Epigraphie, t. II, 1954, p. 161-168.

\section{INDEX}

Mots-clés : Algérie, Antiquité, Christianisme, Histoire, Onomastique 